\title{
3D DOCUMENTATION OF CULTURAL HERITAGE: THE CASE STUDY OF BANTEAY SREI TEMPLE IN ANGKOR, SIEM REAP
}

\author{
L. Zhang ${ }^{1}$, F. Wang ${ }^{1}, *$ X. Cheng ${ }^{2}$, C. Li $^{1}$, H. Lin ${ }^{1}$, Y. Song ${ }^{1}$ \\ ${ }^{1}$ Guangzhou Urban Planning \& Design Survey Institute, No.10, Jianshe Damalu, Guangzhou 510060, China - tjzls@tongji.edu.cn \\ ${ }^{2}$ College of Surveying and Geo-Informatics, Tongji University, No. 1239, Siping Road, Shanghai 200092, China - \\ cxj@tongji,edu.cn
}

KEY WORDS: 3D documentation, Laser scanning, Photogrammetry, Banteay Srei temple, Scene roaming,

\begin{abstract}
:
3D documentation and visualization of cultural heritage has a great significance in preserving the memories and history, and supports cultural tourism. It is of great importance to study the 3D reconstruction of cultural relics and historic sites. Preservation, visualization of valuable cultural heritage has always been a difficult challenge. With the developments of photogrammetry, terrestrial laser scanning, 3D models were able to obtained quickly and accurately. In this paper we present the survey and 3D modelling of an ancient temple, Banteay Srei, situated in Angkor, which has long been admired as a "Precious Gem" of Khmer Art for its miniature size of structures and exceptional refinement of the sculptures. The survey was performed with FARO Focus ${ }^{3 \mathrm{D}} 330$ and FARO Focus ${ }^{3 \mathrm{D}} 120$ terrestrial laser scanners, a micro unmanned aerial vehicle (UAV) (DJI Phantom 4 Pro) and a digital camera (Nikon D90). Once the acquired scans were properly merged, a 3D model was generated from the global point cloud, and plans, sections and elevations were extracted from it for restoration purposes. A short multimedia video was also created for the "Digital Banteay Srei”. In the paper we will discuss all the steps and challenges addressed to provide the 3D model of Banteay Srei Temple.
\end{abstract}

\section{INTRODUCE}

Currently, as a part of cultural heritage enhancement process, the $3 \mathrm{D}$ documentation of historic sites plays a more and more important role for the monitoring and restoring of the site, as well as for popular-informative and educational purposes. In the last decades, we have witnessed the development of the 3D survey techniques: close-range photogrammetry, laser scanning et al. These techniques not only improve the accuracy of the results but also reduce time in a great deal. Digital photogrammetry and laser scanning (Lambers, Eisenbeiss, and Sauerbier 2007)were used to 3D modelling of Pinchango Alto, Peru. Using terrestrial laser scanners, the survey and 3D model of Porta Savonarola were obtained, and 3D solid model was generated from the global point cloud(Guarnieri et al. 2017). Many works published so far have demonstrated 3D survey techniques have great advantage in documentation, preservation and restoration of cultural heritage (Galeazzi 2016; Dhonju et al. 2017; Bruno, Coïsson, and Cotti 2017; Tesi et al. 2017; Pieraccini, Guidi, and Atzeni 2001; Guidi et al. 2009).

Laser scanning, which is completeness, accuracy and fastness rapidly has a wide range of application in the cultural heritage documentation and conservation. UAV is playing an extremely important role in cultural heritage documentation for its costeffective and efficient manner to acquire high spatial resolution data and realistic. In recent years, UAV has significant advances in equipment capabilities. Advanced UAV products have the capacity to acquire high resolution imagery from many angles in a cost effective, efficient manner. Close-range photogrammetry technique can produce a photorealistic 3D model of an object. Its flexibility in data acquisition makes it a quite favourable technique in the cultural heritage field. Besides, compared to other 3D modelling techniques, close-range photogrammetry is more affordable and operable. The rapid development of software has greatly expanded the scope of photogrammetry application, while reducing the cost of acquiring, processing, and analysing acquired images.

In fact, with a single technique mentioned above is not able to deliver satisfactory results, therefore a fusion methodology (of data and sensors) is normally required and performed. In this project, we combined all these techniques mentioned above and make the full advantage of them to generate a satisfied result. The remainder of the paper is organized as follows. In section 2 a short overview of Banteay Srei is presented. Then in section 3 we describe the approach adopted to survey the ancient gate with terrestrial laser scanners. This leads to a discussion on employed data processing techniques in section 4 and achievements in section 5. Finally, in section 6 the paper ends with a short discussion and some concluding remarks.

\section{THE STUDY SITE: BANTEAY SREI TEMPLE}

Banteay Srei Temple, situated in the area of Angkor, has long been admired as a "Precious Gem" of Khmer Art for its miniature size of structures and exceptional refinement of the sculptures (Fig.1). It was consecrated in 967 A.D., the only major temple at Angkor not built for the king. Banteay Srei's architectural style is a mix of the archaic and the innovative. It was built largely of red sandstone, a medium that lends itself to the elaborate decorative wall carvings which are still observable today.

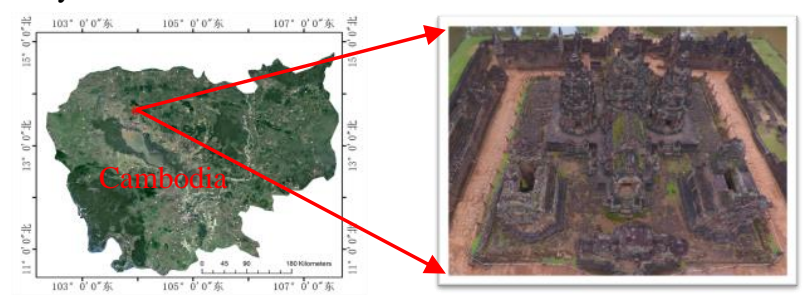

Figure 1. Banteay Srei Temple

\footnotetext{
* Corresponding author
} 


\section{DATA ACQUISITION}

On 27-28 September 2017 and 16-18 August 2018, a field survey was conducted at the Banteay Srei Temple. To be mentioned, prior to the field survey, a brief scouting and scan plan were made. Two different types of terrestrial laser scanner (TLS) manufactured by Faro (Faro Focus3D 330 and Faro Focus3D 120), a micro unmanned aerial vehicle (UAV) (DJI Phantom 4 Pro) and a digital camera (Nikon D90) were applied for data acquisition (Fig. 2).

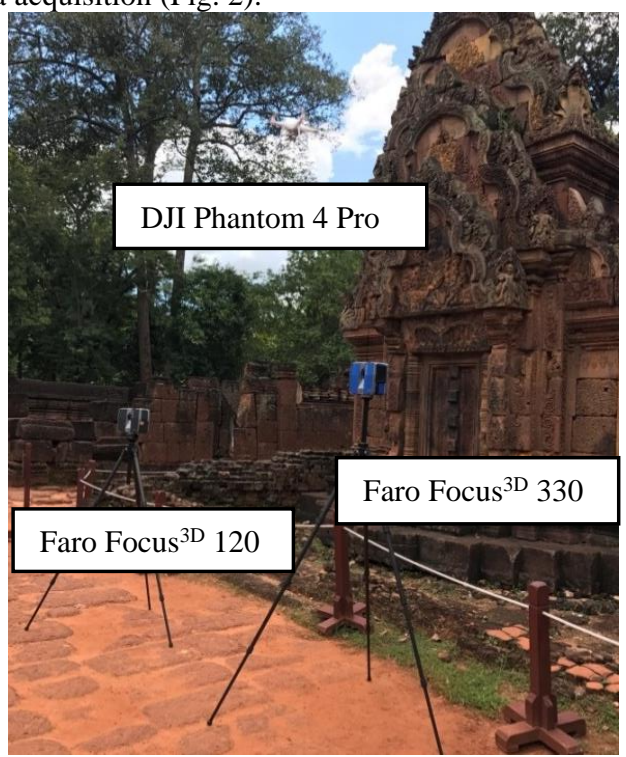

Figure 2. The sensors used for the 3D documentation project

\subsection{TLS Survey}

Two laser scanners were used for acquiring point cloud data of the main architectural structures in the Banteay Srei Temple. Before scanning campaign, the scanners' setup was determined to meet the requirement of the results. The locations of the scanning station were also determined in advance to ensure the complete acquisition of the scanned target (Fig.3 and Fig.4). The number of stations is listed in Table 1 .

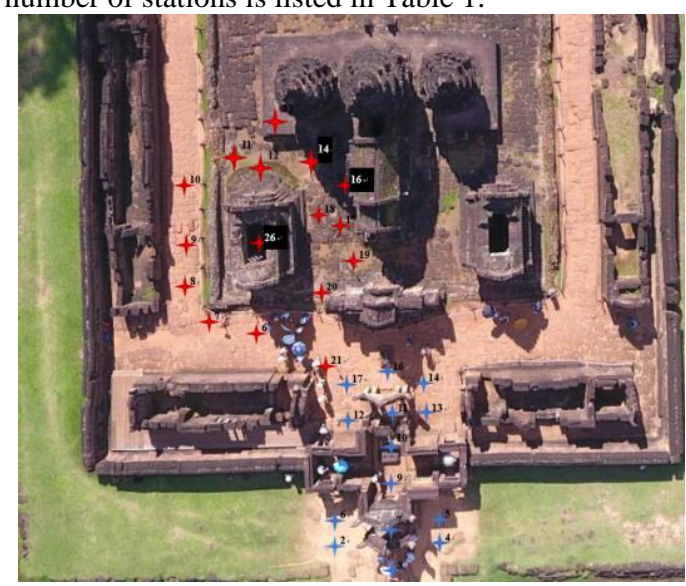

Figure 3. Field survey on 27-28 Sep. 2017

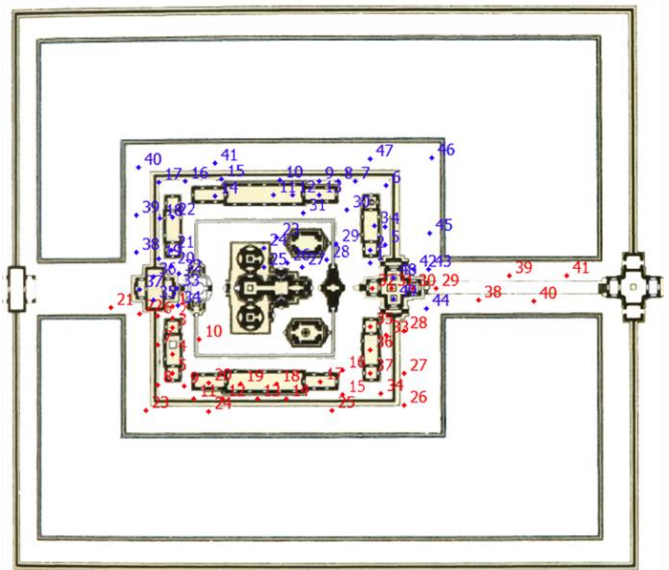

Figure 4. Field survey on 16-18 Aug. 2018

\begin{tabular}{|c|c|c|}
\hline Device & Color & Number of stations \\
\hline Faro Focus $^{3 \mathrm{D}} 120$ & Red & 58 \\
\hline Faro Focus $^{3 \mathrm{D}} 330$ & Blue & 68 \\
\hline Total & - & 126 \\
\hline
\end{tabular}

Table 1. Number of stations from TLS

\subsection{UAV Flight}

The UAV flight was performed on 27th and 28th September. For taking images of the whole site, the UAV was flown over the site at a height of approximately 80 meters from the ground. For the structure roof, it was about 15 meters. The flight planning software with the UAV provided a pre-determined flight path to be followed, thus ensuring significant image coverage and overlap for generation of stereo-pairs of images. The UAV camera took images with an $80 \%$ overlay within each image. In this way, these images can be further utilized to generate an orthophoto of the whole site. Totally 805 images were taken on both days. Samples of the UAV images are shown in Figure 5.

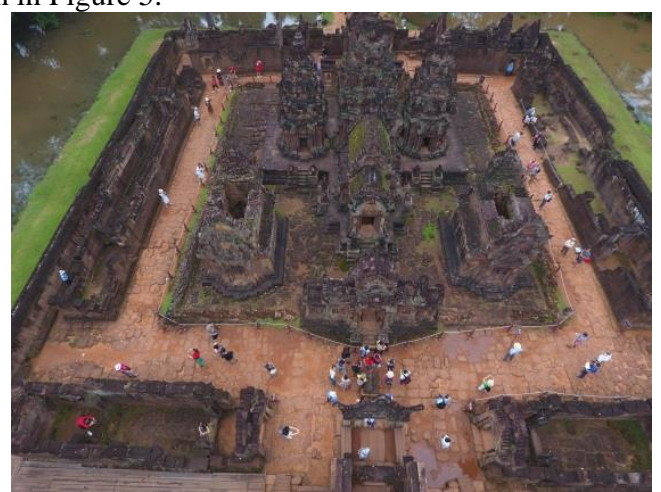

Figure 5. Images taken by UAV

\subsection{Close-range Photogrammetry}

The close-range images were employed to model the small architectural structures and statues and derive detailed and relatively high-resolution $3 \mathrm{D}$ models of them. The images were taken by the Nikon D90 on 28th September and totally 86 images were taken (Figure 6 shows some of the pictures taken). The acquisition of digital images considered the desired coverage of whole target. The images were taken with high overlap each step to acquire enough data for the 3D modelling. 


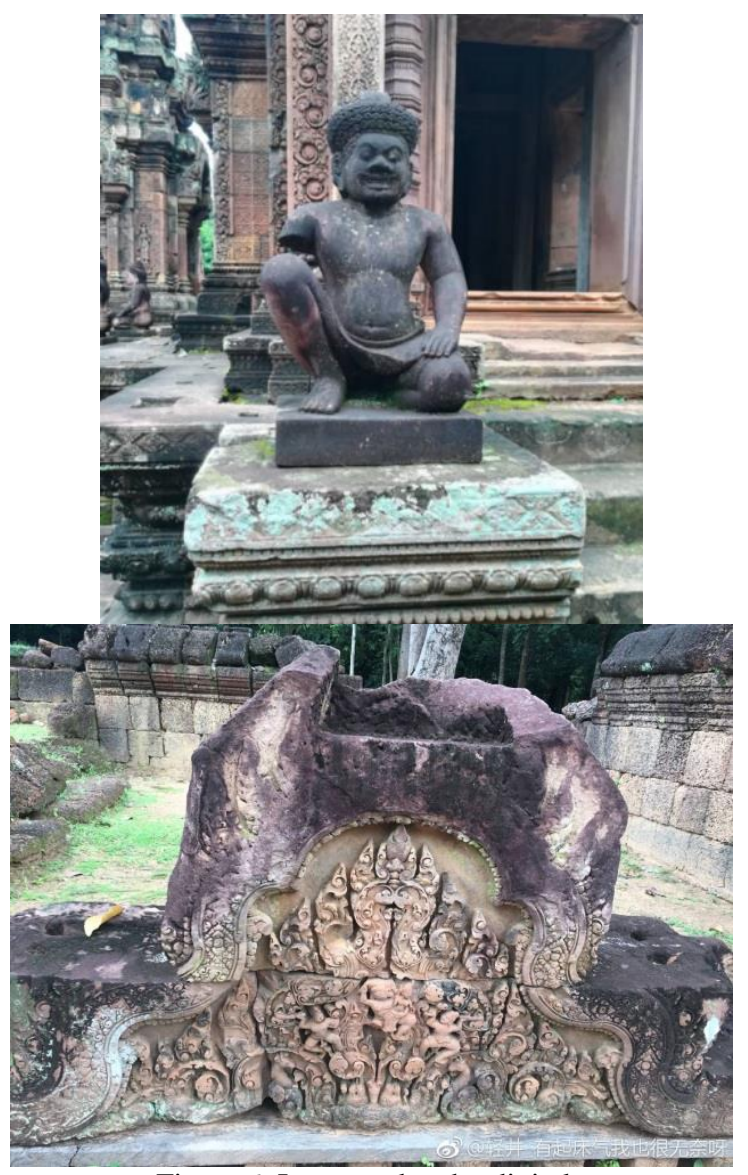

Figure 6 . Images taken by digital camera

\section{DATA PROCESSING}

After the field data acquisition, a series of data processing work (Fig. 7) were conducted by our team member within two months.

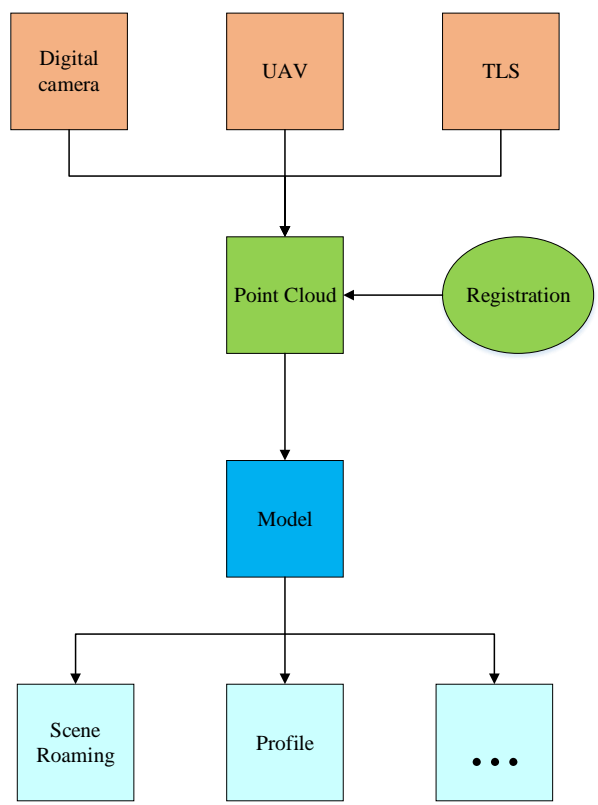

Figure 7. Flow chart

\subsection{TLS Point Cloud Processing}

The procedure forms the point cloud to the 3D model mainly includes point cloud registration, denoising, down sampling and $3 \mathrm{D}$ reconstruction, texture mapping. Following are the details about some specific processing techniques.

\subsubsection{Point Cloud Registration}

To obtain the complete information of the scanned target, multiple scan stations need to be set up. The multiple scans have their own local coordinate systems and need to be integrated to the same coordinate system to generate a complete point cloud which can be further used for the 3D modelling. Below in Figure 8 illustrates two different scans for the same target.

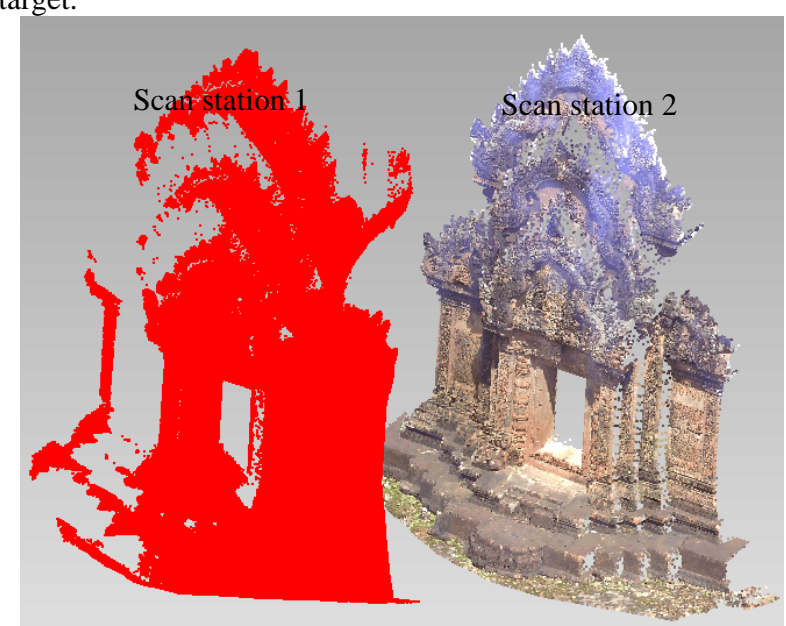

Figure 8 . Two scans before registration

In order to achieve a good registration result, we apply a coarse to fine registration strategy. Firstly, the coarse registration was completed in the Faro Scene software using the featured based registration method. The coarse registration result of the above two scans is shown below in Figure 9. As we can see in Figure 9, errors still occur in the coarse registration, those two scans are not perfectly matched.

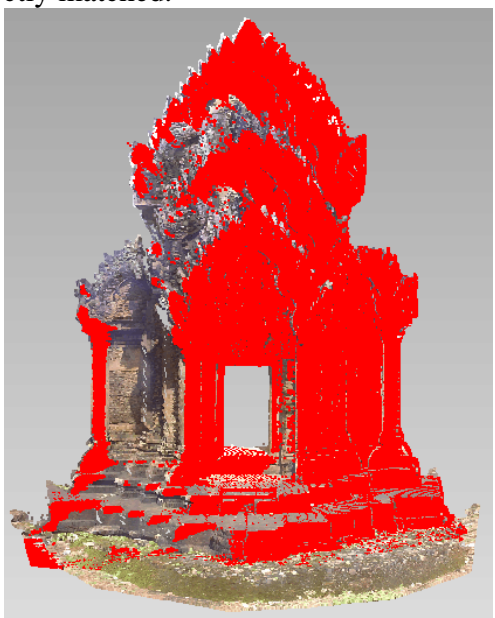

Figure 9. Coarse registration result

The fine registration was conducted through an optimized ICP algorithm to further improve the result. The traditional ICP minimizes the predefined error function by an iterative optimization process, and each iteration of it can be divided into two steps, which are searching for the correspondence and 
calculating the transformation. It is based on a basic assumption that the closest point is the corresponding point by Euclidean distance. However, it is rather difficult to get two relatively consistent sets of points in actual measurement, so the corresponding point is difficult to be got accurately. Besides, the ICP algorithm has difficulties in situations of differing point density. To get better registration results, in our project, an optimized ICP algorithm has been developed. The optimized ICP algorithm can provide quick and accurate registration results, as shown in Figure 10.

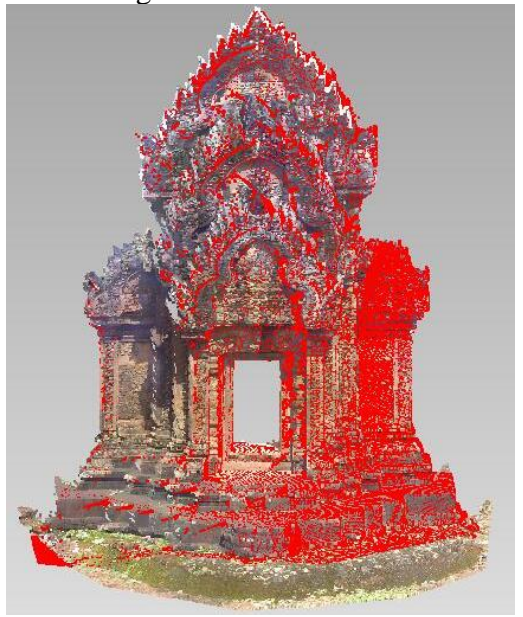

Figure 10. Fine registration result

\subsubsection{D Modelling}

Geomagic Studio software was used to perform the 3D modelling of the architectural structure. The whole procedure mainly includes denoising, down sampling, triangulating, cavity repairing, texturing and mesh generating. The point cloud data of the target was first loaded in the software, then after preprocessing like denoising, down sampling, the triangular mesh was generated (Fig.11).

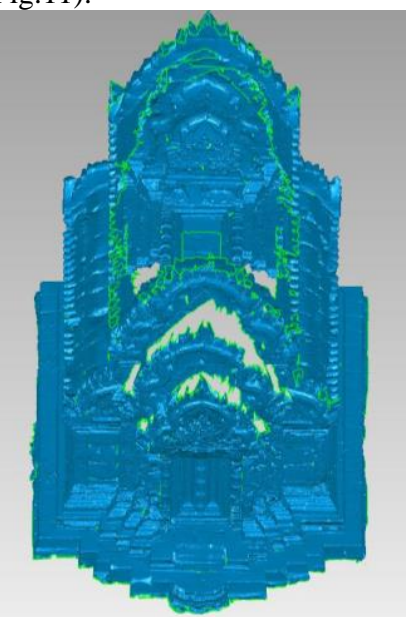

Figure 11. The triangular mesh generated from TLS data

Although the TLS capture the main structure of the whole target the roof of it cannot be scanned due to the scanning geometry. To build a complete model, the UAV data were used to supplement the TLS data. To merge two data, the UAV images were processed with the Agisoft PhotoScan software, which is a stand-alone software product that can perform photogrammetric processing of digital images and generate dense 3D point cloud. The dense point cloud generated from UAV images and the TLS point cloud are from two different coordinates. To merge these two data, first several corresponding featured points were selected manually. Coarse registration was performed by feature based method. Then the advanced ICP was applied to the fine registration of these two data.

Afterward, cavity repairing was performed to fill the small holes in the mesh. Then the images after color-balancing were used to texture the model. Figure 12 illustrates the final model from different views.

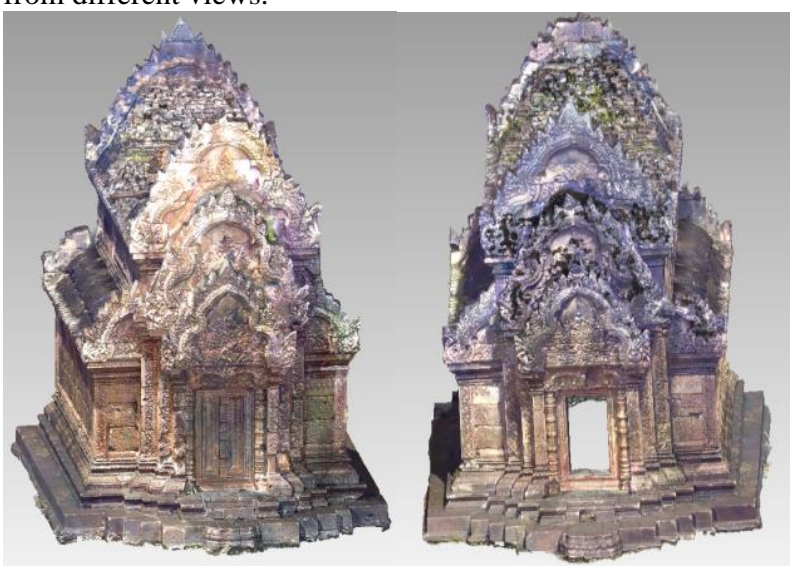

Figure 12. The final 3D model from different views

\subsubsection{Sectional Drawings}

The horizontal section not only contains vector elements of the structure, but also includes attribute information such as material information, dimensioning, and finishing elements. The horizontal section can accurately and intuitively express the true state of the building, so it has a important role in protecting historical buildings. The model generated has been then imported in a CAD environment to manually produce traditional 2D sectional drawings (Fig.13).

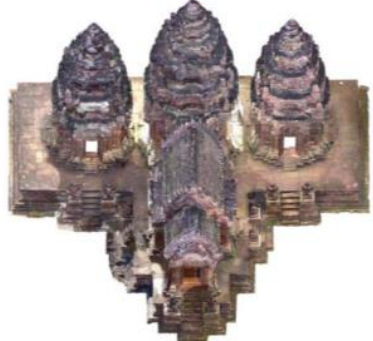

(a) 3D model

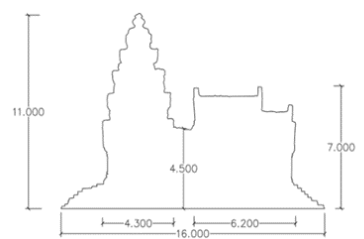

(c) Section

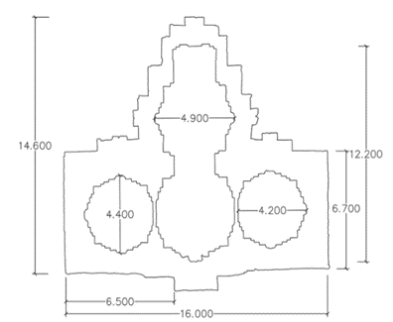

(b) Plan

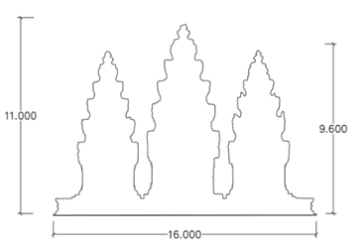

(d) Elevation
Figure 13. The 3D model of Banteay Seri and plan, section and elevation.

\subsubsection{Close-range Images Processing}

The close-range images were also processed with the Agisoft PhotoScan software. With abundant images taken, the dense point cloud of the target was generated which were further 
utilized in 3D modelling. To perform the 3D modelling fast and efficiently, Meshlab, an open source system for processing and editing 3D triangular meshes was used. With standard 3D modelling procedure from editing, cleaning, texturing to converting meshes, the final $3 \mathrm{D}$ models can be generated. Figure 14 shows the 3D model we generated from the closerange images.

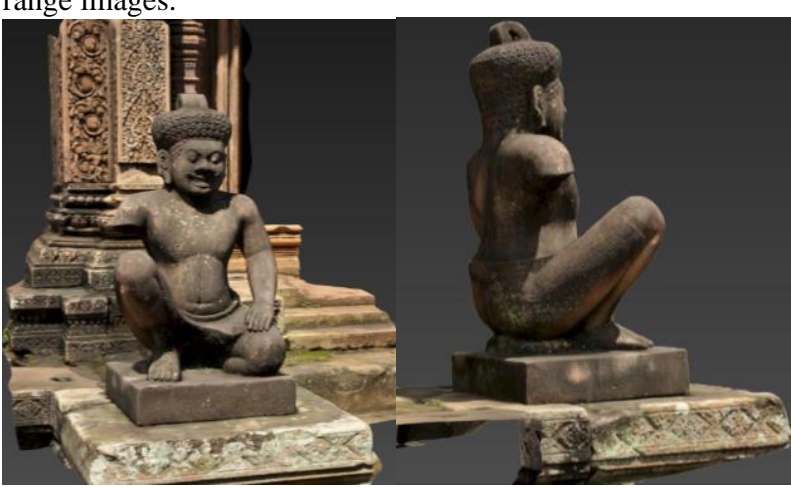

Figure 14. The 3D model of the statue from different views

\subsubsection{Scene Roaming}

Lumion is used to make a rendering roaming scene of Banteay Srei. Through materials, light, plants, scenery and other elements, it can generate a more realistic Scene rendering of Banteay Srei (Fig. 15). A short multimedia video was also created for the "Digital Banteay Srei".

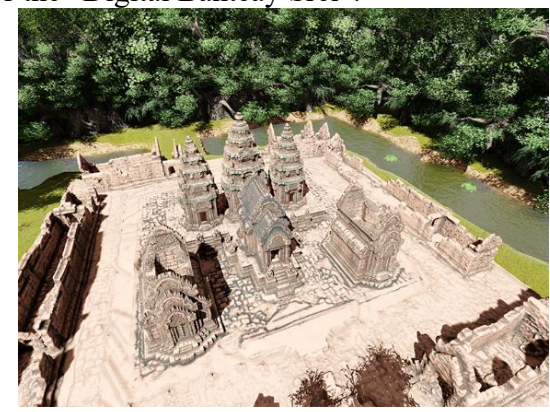

Figure 15 . Scene roaming

\section{CONCLUSION AND DISCUISSION}

In this work we present a sequence of procedures that were performed to produce orthophoto and 3D models of the heritage site of Banteay Srei, and some specific architectural structures and statues that are there. We use a combination of technologies to document this fabulous cultural heritage and provide Authority for the Protection and Management of Angkor and the Region of Siem Reap (APSARA) information to help them make the most efficient tasks as: preserving they archaeological artifacts, natural resources and other around the temple area With the 3D models generated, it is possible to know the structure of heritage in detail at ground level. Furthermore, it can also provide a way to transmit knowledge about the heritage sites to future generations.

In the procedure of this work, we have encountered some problems: color-balancing problem. When we picked up the images with color distortion, we found that some of the pictures were overexposed due to the strong sunlight. The color information was missing in these images and cannot be restored Moreover, although the color of a single TLS station can be repaired with color-balancing, the color among different TLS scan stations also varied a lot due to different illumination angles. Thus, in our future work, we may find a solution to deal with the color-balancing among different TLS scan stations.

\section{ACKNOWLEDGEMENTS}

The data analysis presented in this article was thanks to the 3D data collection conducted at Banteay Srei Temple (Cambodia) in 2017\&2018. For this reason, We would like to thank Authority for the Protection and Management of Angkor and the Region of Siem Reap (APSARA), that allowed us to use Banteay Srei Temple for our research. Special thanks go also to TIN Tina and KIM Samnang for the help and assistance during the 3D data acquisition. This work was supported by Guangzhou Science and technology plan (201704030102).

\section{REFERENCES}

Bruno, N., E. Coïsson, and M. Cotti. 2017. 'Laser-Scanner Survey of Structural Disorders: An Instrument toInspect the History of Parma Cathedral's Central Nave', ISPRS International Archives of the Photogrammetry, Remote Sensing and Spatial Information Sciences, XLII-5/W1: 167-74.

Dhonju, H. K., W. Xiao, B. Shakya, J. P. Mills, and V. Sarhosis. 2017. 'Documentation of Heritage Structures through GeoCrowdsourcing and Web-Mapping', ISPRS - International Archives of the Photogrammetry, Remote Sensing and Spatial Information Sciences, XLII-2/W7: 17-21.

Galeazzi, Fabrizio. 2016. 'Towards the definition of best 3D practices in archaeology: Assessing 3D documentation techniques for intra-site data recording', Journal of Cultural Heritage, 17: 159-69.

Guarnieri, A., F. Fissore, A. Masiero, and A. Vettore. 2017. 'Fom tls survey to 3D solid modeling for documentation of built heritage: the case study of porta savonarola in padua', ISPRS International Archives of the Photogrammetry, Remote Sensing and Spatial Information Sciences, XLII-2/W5: 303-08.

Guidi, Gabriele, Fabio Remondino, Michele Russo, Fabio Menna, Alessandro Rizzi, and Sebastiano Ercoli. 2009. 'A Multi-Resolution Methodology for the 3D Modeling of Large and Complex Archeological Areas', International Journal of Architectural Computing, 7: 39-55.

Lambers, Karsten, Henri Eisenbeiss, and Martin Sauerbier. 2007. 'Combining photogrammetry and laser scanning for the recording and modelling of the Late Intermediate Period site of Pinchango Alto, Palpa, Peru', Journal of Archaeological Science, 34: 11.

Pieraccini, Massimiliano, Gabriele Guidi, and Carlo Atzeni. 2001. '3D digitizing of cultural heritage', Journal of Cultural Heritage, 2: 63-70.

Tesi, V., G. Tucci, V. Bonora, L. Fiorini, and A. Conti. 2017. 'Laser Scanning and Modelling of Barely Visible Features: The Survey of the Grotto of the Animals at the Villa of Castello (Florence)', ISPRS - International Archives of the Photogrammetry, Remote Sensing and Spatial Information Sciences, XLII-5/W1: 343-49. 